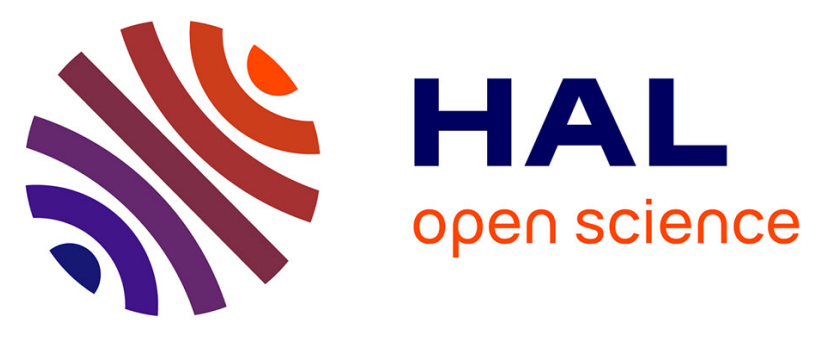

\title{
Development and preliminary validation of a new instrument to assess eating behaviors: The virtual self-service restaurant (VSSR)
}

Stéphanie Scoffier-Mériaux, Christophe Gernigon, Emmanuel Billi, Fabienne d'Arripe-Longueville

\section{To cite this version:}

Stéphanie Scoffier-Mériaux, Christophe Gernigon, Emmanuel Billi, Fabienne d'Arripe-Longueville. Development and preliminary validation of a new instrument to assess eating behaviors: The virtual self-service restaurant (VSSR). Science \& Sports, 2013, 28 (3), pp.140-145. 10.1016/j.scispo.2012.03.003. hal-02524814

\section{HAL Id: hal-02524814 \\ https://hal.univ-cotedazur.fr/hal-02524814}

Submitted on 3 Apr 2020

HAL is a multi-disciplinary open access archive for the deposit and dissemination of scientific research documents, whether they are published or not. The documents may come from teaching and research institutions in France or abroad, or from public or private research centers.
L'archive ouverte pluridisciplinaire HAL, est destinée au dépôt et à la diffusion de documents scientifiques de niveau recherche, publiés ou non, émanant des établissements d'enseignement et de recherche français ou étrangers, des laboratoires publics ou privés. 


\section{Elsevier Editorial System(tm) for Science \& Sports}

Manuscript Draft

Manuscript Number: SCISPO-D-11-00128R1

Title: Development and Preliminary Validation of a New Instrument to Assess Eating Behaviors: The Virtual Self-Service Restaurant (VSSR)

Article Type: Full Length Article

Keywords: Eating attitudes, energy expenditure and intake, virtual interface, sport, health prevention programs.

Corresponding Author: Dr Stéphanie Scoffier,

Corresponding Author's Institution: UNIVERSITY OF NICE SOPHIA ANTIPOLIS

First Author: Stéphanie Scoffier

Order of Authors: Stéphanie Scoffier; CHRISTOPHE GERNIGON; EMMANUEL BILLI; FABIENNE

D'ARRIPE-LONGUEVILLE

Abstract: Objectives: The aim of this study was to develop a computerized instrument to assess eating attitudes and behaviors, the "Virtual Self-Service Restaurant" (VSSR), and to test for preliminary evidence of its validity. Improved measures of self-regulation in this area should facilitate the management of individuals with eating disorders, particularly athletes, and the implementation of tailored prevention and intervention programs.

Results: This interface assesses the individual's basal metabolism, energy expenditure related to physical activity, global energy expenditure, global energy intake (i.e., difference between energy expenditure and intake), and distribution of food intake over the day. The validity of the Virtual SelfService Restaurant was tested in four populations, and the results indicated satisfactory internal and external validity.

Conclusion: This instrument, which shows preliminary evidence of validity and reliability, can be used to promote educational nutrition programs for sedentary and athletic populations. 
Running head: Virtual restaurant self-service validation

Development and Preliminary Validation of a New Instrument to Assess Eating Behaviors: The Virtual Self-Service Restaurant (VSSR)

Développement et validation préliminaire d'un nouvel instrument d'évaluation des comportements alimentaires: le restaurant virtuel

\author{
Stéphanie Scoffier \\ University of Nice Sophia Antipolis LAMHES, France \\ Christophe Gernigon \\ University of Montpellier I, France
}

Emmanuel Billi, \& Fabienne d'Arripe-Longueville

University of Nice Sophia Antipolis, LAMHES, France

Corresponding author:

Stéphanie Scoffier

UFR STAPS - University of Nice Sophia-Antipolis

261 Route de Grenoble, BP 3259

06205 Nice cedex 03, France

Phone: ++ 33492296529

Fax: ++ 33492296537

Email: scoffier@unice.fr

Date of revision: March 13, 12 
2 Objectives: The aim of this study was to develop a computerized instrument to assess eating

3 attitudes and behaviors, the "Virtual Self-Service Restaurant" (VSSR), and to test for

4 preliminary evidence of its validity. Improved measures of self-regulation in this area should

5 facilitate the management of individuals with eating disorders, particularly athletes, and the

6 implementation of tailored prevention and intervention programs.

7 Results: This interface assesses the individual's basal metabolism, energy expenditure related

8 to physical activity, global energy expenditure, global energy intake (i.e., difference between

9 energy expenditure and intake), and distribution of food intake over the day. The validity of

10 the Virtual Self-Service Restaurant was tested in four populations, and the results indicated

11 satisfactory internal and external validity.

12 Conclusion: This instrument, which shows preliminary evidence of validity and

13 reliability, can be used to promote educational nutrition programs for sedentary and athletic 14 populations.

16 Keywords: Eating attitudes, energy expenditure and intake, virtual interface, sport, health 17 prevention programs. 
3 Objectifs : Le but de cette étude était de développer et valider de manière préliminaire un

4 instrument informatisé pour évaluer les attitudes et les comportements alimentaires, le «

5 Virtual Self-Service Restaurant » (VSSR). L'amélioration des mesures de l'autorégulation des

6 comportements alimentaires devrait permettre de mieux accompagner les individus en

7 général, et les athlètes en particulier, en mettant en œuvre des programmes d'intervention et de 8 prévention adaptés.

9 Résultats : Cette interface permet d'évaluer le métabolisme basal de l'individu, la dépense 10 énergétique liée à l'activité physique, la dépense énergétique globale, l'apport

11 énergétique global (i.e., différence entre les dépenses et les apports énergétiques), et la 12 répartition de l'apport alimentaire au cours de la journée. La validité du self virtuel a été 13 examinée auprès de quatre populations. Les validités interne et externe du VSSR se sont 14 révélées satisfaisantes.

15 Conclusion : Cet instrument qui a démontré des premiers indicateurs de validité et de 16 fiabilité, pourra être utilisé pour promouvoir des programmes d'éducation 17 nutritionnelle auprès de populations sédentaires ou sportives.

19 Mots-clés: attitudes alimentaires, dépense et apport énergétiques, interface virtuelle, sport, 20 programmes de prévention-santé. 
1 Development and Preliminary Validation of a New Instrument to Assess Eating Behaviors:

The Virtual Self-Service Restaurant (VSSR)

The prevalence of eating disorders has become quite high among athletes in certain sports (e.g., aesthetic sports, weight class sports, endurance sports). These sports often require frequent weight checks and complex training regimes. For instance, athletes in aesthetic sports have to conform to an ideal body weight in order to achieve an esthetically pleasing appearance and performance excellence [1]. Although many athletes initially experience an improvement in sports performance with weight loss, this improvement is generally shortlived if it was due to a drastic reduction in food intake. A major decrease in food consumption depletes energy and can be indicative of an eating disorder. Athletes in high-risk sports and others suspected of having an eating disorder should be quickly assessed and treated if necessary. More generally, it is likely that helping athletes and individuals to develop appropriate nutritional strategies to attain a desirable body profile, weight, strength, and endurance will go far in reducing the future risk of eating disorders [2].

The regulation of eating attitudes is part of the general regulation of energy homeostasis, which maintains a constant fat level. Nevertheless, decisions about what and when to eat are highly individual and vary with the individual's changing situation. In addition to the actual presence of food and the sensation of hunger, many other internal and external cues can activate the desire to eat immediately or direct the person to the choice of certain foods [3]. Indeed, the literature in social psychology and sport psychology indicates that disordered eating attitudes are developed from a complex interaction of personal (e.g., anxiety, perfectionism, self-esteem) and contextual (e.g., media influence, peer social acceptance) factors [4-5]. 
Several instruments for assessing eating attitudes are commonly used in psychology

2 research. Garner, Olmsted, Bohr and Garfinkel's scale [6], validated in French by Leichner,

3 Steiger, Puentes-Neuman, Perreault and Gottheil [7], is a well-known measure of disturbed

4 eating attitudes and behaviors with 26 items on three subscales: (a) eating restriction, (b)

5 bulimia and food obsession, and (c) control of eating. Garner, Olmsted and Polivy's [8] Eating

6 Disorder Inventory (EDI) presents an inventory of the traits associated with eating disorders

7 and thus measures the drive for thinness, bulimia, body dissatisfaction, ineffectiveness,

8 perfectionism, interpersonal distrust, interoceptive awareness, maturity fears, and

9 psychopathologic symptoms. In a recent review of the psychological assessment of eating 10 disorders, Drew and Paulosky [9] noted that Van Strien, Frijters, Bergers and Defares' [10]

11 Dutch Eating Behavior Questionnaire and Smith and Thelen's [11] Bulimia Test Revised were 12 frequently used self-reported measures. Drew and Paulosky [9] also mentioned the use of 13 semi-structured interviews such as Fairburn and Cooper's [12] Eating Disorder Examination, 14 which assesses the symptoms of anorexia nervosa and bulimia nervosa, as well as the 15 symptoms related to psychopathology. Drew and Paulosky [9] also presented behavioral 16 measures of eating disorders such as Wilson and Vitousek's [13] Self Monitoring instrument 17 and Williamson's [14] Test Meals, while acknowledging that these two methods are not used 18 much because of the difficulty in implementing them.

20 attitudes in daily life [e.g., Pinto, Guarda et al.'s [15] Eating Disorder Recovery Self-Efficacy 21 Questionnaire (EDRSQ)] and in sports (Scoffier, Paquet, Corrion, \& d'Arripe-Longueville's 22 [16] Self Regulatory Eating Attitudes Scale in Sport). The instrument of Scoffier et al. [16] is 23 composed of 16 items which are loaded onto five factors pertaining to the self-regulation of 24 eating behavior in the following contexts: (a) food temptation, (b) negative situations, (c) 
1 social interaction, (d) lack of compensatory strategies, and (e) lack of anticipation of consequences on performance.

4 identified: Tools have also been developed for dietary assessment [17]. Five categories can be

6 advantages such as: quantification of food intake, no requirement to recall foods eaten,

7 appropriateness for most populations, information on total diet, and low investigator cost.

8 They also present several disadvantages such as: high investigator cost, many days needed to

9 capture an individual's usual intake, difficulty of the cognitive task for respondents, and 10 frequent misreporting of intakes.

According to Title IV of the Code of Conduct of the French Society of Psychology for researchers in the behavioral sciences, direct observation of the attitudes and behaviors related to eating disorders is unethical. The tools currently in use are thus based on the self-reported level of eating disorder (i.e., the levels of various components of eating disorders) [6, 8], the self-reported ability to control eating behaviors or attitudes [15-16], or the food record or diet history, which carries high investigator cost or the risk of often misreported intakes. Such instruments, which depend on personal assessment, may generate social desirability bias when they are used to assess sensitive or taboo matters like one's relationship to food.

Given the specific issues and social influences pertaining to eating behaviors, the existing tools thus have obvious limitations. The development and validation of a specific tool, such as a virtual interface allowing subjects to individually project their eating habits, seemed necessary to better assess, explain and prevent eating disorders. Indeed, such a tool could help individuals and athletes to more easily assess their usual food intakes and energetic expenditure via an ergonomic interface. The aim of this study was therefore to develop and 
1 validate a computerized instrument to assess actual food intake (i.e., food choice, amount

2 eaten, meal sizes and meal frequency): the "Virtual Self-Service Restaurant", to enable

3 individuals to compose virtual meals by selecting food through a graphical user interface. Our

4 intention was to provide better assistance to researchers and therapists in measuring the food

5 intake of, respectively, their participants and patients. The virtual projection of an eating

6 attitude is personal and without social or environmental pressure because the participant can

7 complete the activity at the most convenient time on the Internet. The self-service restaurant

8 was developed and validated in successive stages: (a) elaboration of the interface, (b)

9 assessment of its clarity, and (c) assessment of its internal and external validity.

\section{Stage 1: Elaboration of the Virtual Self-Service Restaurant}

The Virtual Self-Service Restaurant is a virtual interface for choosing the composition of five meals a day from a wide range of food offerings (see Appendix 1). Geier and Rozin [18] showed that the evaluation of the caloric content of a meal was biased by the unstandardized units (i.e., the quantity of a portion) and the tendency to choose a single variable for assessing the quantity (i.e., either weight or size). Research in the field of nutrition has shown that, generally, when eating behavior is projected virtually individuals ignore the thickness of a piece of food and concentrate on its size [19], and judgments of size tend to decrease as the absolute size increases [20]. In addition, individuals develop rules for evaluating the number of calories based on what seems to be a standard size for the food in question [21], and foods perceived as healthier are assumed to have lower caloric density [20]. Thus, in order to curb these biases in the virtual screening of food intake and to obtain quantity assessments that are as accurate as possible, the Virtual Self-Service Restaurant does not mention the number of calories but refers only to the type of container (e.g., glass, bowl, soup spoon). The perception of the quantity of each food chosen by the participants is based on personal eating habits using measured quantities from a container. A picture is used as a 
1 guide for each food. Two sport dietitians who viewed this method as an appropriate means for

2 assessing athletes' food habits agreed to evaluate the interface.

This interface assesses: (a) basal metabolism using Black, Coward, Cole and

4 Prentice's [22] equation, ${ }^{1}$ (b) the energy expended for physical activity, and (c) the overall

5 energy expenditure. Regarding the energy expended for physical activity, we used the

6 compendium of physical activity of Ainsworth and colleagues [23], which comprises 80

7 sports at several intensities (i.e., the participant specifies the type of activity and provides the

8 number of hours and minutes performing the activity; the software then estimates the

9 energetic requirement averaged base on a table of physical activity of energetic expenditures

10 in relation to anthropometric measurements, as based on the dietary calculations). The overall

11 energy intake is assessed from the food choices made for a given day, and all these data are

12 then used to calculate the difference between energy expenditure and energy intake and the 13 distribution of food intake throughout the day. The calculation of the difference between

14 energy intake and energy expenditure can provide the self-regulation of eating attitudes.

15 When energy intake and expenditure are balanced, good self-regulation of eating attitudes can

16 be assumed. With increasingly greater imbalance between energy intake and expenditure,

17 increasingly less optimal self-regulation of eating attitudes should be suspected.

2. Stage 2: Study of the clarity of the Virtual Self-Service Restaurant

The clarity of the interface of the Virtual Self-Service Restaurant was tested on 15

23 Virtual Self-Service Restaurant clear? Are the food choices easy to make? Are the food

\footnotetext{
${ }^{1}$ [i.e., Male $=[1.083 \times$ Weight $(\mathrm{kg}) .48 \times$ Height $(\mathrm{m}) .50 \mathrm{x}$ Age $(\mathrm{yr})-.13] \mathrm{x}(1000 / 4.1855) ;$ Female $=[.963 \mathrm{x}$ Weight (kg) .48 x Height (m) .50 x Age (yr)- .13] x (1000/4.1855)]; kg: kilograms, m: meters.
} 
1 images representative? Is the way the food quantities are presented appropriate for composing

2 meals? Is the number of individual foods offered sufficient?). Each item was assessed with a

3 Likert-type scale on four points from 1 (Not at all) to 4 (Totally). All participants attributed 3

4 or 4 points to each item, which strongly indicated the overall clarity of the tool $\left(M_{\text {age }}=3.80\right.$; $5 S D=.41)$.

Based on interviews with the participants in the clarity test, some adjustments in terms of describing quantities were made to improve the ease of use. Thus, sauces to add flavor to food were added, and their caloric value, although masked for participants, was calculated.

\section{Stage 3: Study of the internal and external validity of the Virtual Self-Service}

\section{Restaurant}

The aim of this third stage was to assess the internal and external validity of the Virtual Self-Service Restaurant. The internal validity was tested in four samples: (a) adolescents, (b) adolescent athletes in high-risk sports, (c) adolescent athletes in other sports, and (d) adults. Therefore, the external validity of the Virtual Self-Service Restaurant was asserted among all internal validity assessment.

\subsection{Method}

Participants. Four groups of participants were asked to test the applicability of this instrument to their respective populations: adolescents, adolescent athletes in sports in which weight is an important concern, adolescents in other sports, and adults. The sample of adolescents $\left(N=21 ; M_{\text {age }}=13.65 ; S D_{\text {age }}=.65\right)$ was composed of 13 females and 9 males. This group was characterized by an average weight of 131.63 pounds $(S D=34.63)$ and an average height of 5.57 feet $(S D=.07)$. The sample of adolescent athletes in sports in which weight was a major preoccupation (i.e., aesthetic sports, weight-class sports, endurance sports $)\left(N=22 ; M_{\text {age }}=25.31 ; S D_{\text {age }}=4.70\right)$ was also composed of 13 females and 9 males. This group was characterized by an average weight of 131.638 pounds $(S D=34.63)$ and an 
1 average height of 5.57 feet $(S D=.07)$. The sample of adolescent athletes in other sports (i.e.,

2 team sports, dual sports such as tennis $)\left(N=20 ; M_{\text {age }}=26.42 ; S D_{\text {age }}=5.67\right)$ was composed of

312 females and 8 males. This group was characterized by an average weight of 136.90 pounds

$4 \quad(S D=23.54)$ and an average height of 5.54 feet $(S D=.09)$. The sample of adults $(N=23$;

$\left.5 \quad M_{\text {age }}=33.65 ; S D_{\text {age }}=10.49\right)$ was composed of 13 females and 10 males. This group was

6 characterized by an average weight of 146.60 pounds $(S D=29.23)$ and an average height of

$7 \quad 5.61$ feet $(S D=.07)$. day interval: (a) the report of food intake over the course of a day and (b) the Virtual SelfService Restaurant choices. Half of each group thus completed the Virtual Self-Service Restaurant first and the other half completed the food intake report first. For the measure of the actual food intake, each participant recorded all food intakes in a notebook on a specific day. Food intake was converted into energy intake using Diondine $\odot$ software [24]. For the measure of the virtual food intake, each subject visited the Virtual Self-Service Restaurant and made food choices over a full day among the foods offered. Thus, each participant had to choose each component of a meal in terms of quality and quantity (i.e., food types and quantities of energy intake) from among the foods offered as a buffet for each meal (i.e., breakfast, snack, lunch, snack, dinner).

Analysis. We analyzed the recorded energetic intakes and the Virtual Self-Service Restaurant choices for each group using descriptive statistics and the Student $t$ test for paired samples. Moreover, a significant linear regression was used to demonstrate that the two variables were related. The level of significance was retained at $p \leq .05$.

\subsection{Results}

Internal validity in the adolescent sample. The participants documented an average intake of 1925.60 Cal $(S D=590.76)$ in the Virtual Self-Service Restaurant and 1783.45 Cal 
$1 \quad(S D=515.84)$ in the notebook. Thus, we observed an average difference of $-109.40 \mathrm{Cal}(S D=$

2 317.26) between the two measures (i.e., notebook energetic intake - Virtual Self-Service

3 Restaurant energetic intake). However, the Student $t$ test for paired samples was not

4 significant $(t=-.313 ; p=.758)$. The linear regression was significant $(\beta=.93 ; p<.01)$ and

5 demonstrated that the two variables were related.

\section{Internal validity in the sample of adolescent athletes in high-risk sports (aesthetic} sports, weight-class sports, endurance sports). The participants documented an average intake of 1906.90 Cal $(S D=600.66)$ in the Virtual Self-Service Restaurant and 1790.40 Cal $(S D=505.87)$ in the notebook. Thus, we observed an average difference of $-116.50 \mathrm{Cal}(S D=$ 329.37) between the two measures (i.e., notebook energetic intake - Virtual Self-Service

Restaurant energetic intake). However, the Student $t$ test for paired samples was not significant $(t=-1.66 ; p=.11)$. The linear regression was significant $(\beta=.83 ; p<.01)$ and demonstrated that the two variables were related.

\section{Internal validity in the sample of adolescent athletes in other sports (team sports).} The participants documented an average intake of $1718.45 \mathrm{Cal}(S D=479.10)$ at the Virtual Self-Service Restaurant and 1692.45 Cal $(S D=426.73)$ in the notebook. Thus, we observed an average difference of $-26.00 \mathrm{Cal}(S D=196.27)$ between the two measures (i.e., notebook energetic intake - Virtual Self-Service Restaurant energetic intake). However, the Student $t$ test for paired samples was not significant $(t=-.59 ; p=.56)$. The linear regression was significant $(\beta=.91 ; p<.01)$ and demonstrated that the two variables were related.

Internal validity in the sample of adults. The participants documented an average intake of 1875.34 Cal $(S D=451.86)$ in the Virtual Self-Service Restaurant and 1891.30 Cal $(S D=351.80)$ in the notebook. Thus, we observed an average difference between the two measures (i.e., notebook energetic intake - Virtual Self-Service Restaurant energetic intake) of $-15.85 \mathrm{Cal}(S D=191.69)$. However, the Student $t$ test for paired samples was not 
1 significant $(t=.39 ; p=.69)$. The linear regression was significant $(\beta=.92 ; p<.01)$ and

2 demonstrated that the two variables were related.

The results pertaining to all the populations under study revealed no significant differences between the energetic intakes of the Virtual Self-Service Restaurant and the notebook. Therefore, both the internal and external validity of the Virtual Self-Service Restaurant can be asserted.

\section{General Discussion}

The aim of this study was to develop and validate a computerized instrument to assess actual food intake, the "Virtual Self-Service Restaurant", to enable individuals to compose virtual meals by selecting food through a graphical user interface, thereby better assisting researchers and therapists in measuring eating attitudes and behaviors. This new tool captures eating attitudes ecologically without departing from ethical guidelines. The development and validation of the virtual restaurant required three stages: (a) elaborating the Virtual Self-

Service Restaurant, (b) verifying its clarity and (c) demonstrating its internal and external validity.

The preliminary results of this study indicate that the Virtual Self-Service Restaurant is a valid instrument for assessing the following: (a) the basal metabolism of study participants, using the equation of Black et al. [22]; (b) the energy expended for physical activity, with reference to 80 sports at several intensities; and (c) the global energy expenditure. Based on the virtual projection of eating attitudes, we calculated the global energetic intake. Then, using this calculated index, we assessed the difference between energy expenditure and intake and the distribution of food intake over the day.

Several limitations became apparent during the course of this validation study. First, the moment in time and the situational context of an individual at that time undoubtedly contribute to his or her nutritional state and this would also affect the outcome of the virtual 
1 experiment. Moreover, a true picture of an individual's habitual food intake is generally

2 obtained by averaging the daily intakes calculated over a prolonged period of time (weeks or

3 months rather than days) [25]. Studies are thus needed to further test the validity of this

4 instrument using repeated measures and independent samples; with regard to athletes, high

5 skill-level participants should also be included. These results also need to be replicated in

6 larger samples of participants overall, and particularly in larger samples of athletes at-risk and

7 not-at-risk for eating disorders. Future studies should also verify that the scores obtained on

8 this self-reported instrument are significantly related to current or objective measures of food

9 intake. This instrument could be adapted by changing the food selection according to the 10 season of the year, and it could also be adapted to other cultures and translated into other 11 languages to examine its cross-cultural validity.

Second, it is difficult to accurately estimate energy intake. Our inability to obtain good information on food intake could be succinctly described by Blundell [26] as “"(..) a dilemma for nutrition (...) but an enigma for psychology.' Differential reporting of nutrients is the inevitable end result of differential reporting of foods and meals. If dietary assessments are to be improved, we must understand which foods and meals are misreported.

In another way, energy intake is not compared to energy requirement set by energy expenditure. This analysis was not taken into account in this validation study because it would not have allowed us to verify the validity of the instrument. The interpretation of this comparison should be the aim of another study in relationship with the self-regulation of eating attitudes capacities [16].

Because the Virtual Self-Service Restaurant assesses the balance between energetic expenditure and intake, it can be used to measure the self-regulation of eating attitudes in adolescents and adults, as well as in athletes. This interface should be useful for research purposes. For instance, such a tool could be used to follow cohorts in epidemiological 
1 investigations to identify the risk factors for eating disorders. Interventional trials with control

2 group comparison could be conducted, with repeated measures of self-regulation of eating

3 attitudes through the Virtual Self-Service Restaurant. This instrument would also be useful in

4 the prevention of disordered eating by helping individuals to become more aware of their

5 energy needs and the energy intake they virtually plan on a typical day. The Virtual Self-

6 Service Restaurant immediately picks up an imbalance in these two values and can then be

$7 \quad$ used to better regulate feeding behavior through the objectification of these variables.

8 In the sport context, this tool could also help athletes to focus on personal nutritional

9 needs based on day-to-day changes in the schedule of training intensity and volume. Over

10 time, this would develop greater awareness of fluctuating energy requirements and sharpen

11 the athlete's ability to regulate eating behavior over the course of a sport season. An important 12 point is that little time is needed for the Virtual Self-Service Restaurant, making it compatible 13 with the busiest schedules, such as those of elite athletes. Last, the Virtual Self-Service 14 Restaurant indicates the projected distribution of food intake during the day and, particularly 15 for athletes; this can be compared with the distribution of physical activity that day. Ways to 16 optimize the distribution of dietary intake can then be considered. For the other populations, 17 the Virtual Self-Service Restaurant is a valid instrument for enhancing awareness of food 18 intake and its distribution during the day. It thus might be easily adapted for national 19 campaigns to improve nutritional health in different segments of the French population. 
1. Scoffier, S., Maïano, C., \& Arripe-Longueville, F. (d'). The effects of social

relationships and acceptance on disturbed eating attitudes in elite adolescent female athletes: the mediating role of physical self-perceptions. Int J Eat Dis; 2010. 43: 65-71.

2. Bernardot D. Advanced Sports Nutrition, $1^{\text {st }}$ Edition. Champain, IL: Human Kinetics; 2005.

3. Mela, D. J. Determinants of food choice: relationships with obesity and weight control. Obes Res. 2001; 9: 249S-255S.

4. Jacobi C, Hayward C, de Zwaan M, Kraemer HC, Agras S. Coming to terms with risk factors for eating disorders: application of risk terminology and suggestions for a general taxonomy. Psych Bull. 2004; 13: 19-65.

5. Petrie TA, Greenleaf CA. Eating disorders in sport: From theory to research to intervention. In: Tenenbaum G, eds. Handbook of Sport Psychology, 3rd Edition. Hoboken, NJ: J. Wiley \& Sons, Inc, Hoboken; 2007: 352-378.

6. Garner D, Olmsted M, Bohr Y, Garfinkel P. The Eating Attitude Test: psychometric features and clinical correlates. Psychol Med. 1982; 12: 871-878.

7. Leichner P, Steiger H, Puentes-Neuman G, Perreault M, Gottheil N. Validation d'une échelle d'attitudes alimentaires auprès d'une population québécoise francophone [Validation of an eating attitudes scale in a French population from Quebec]. Can Psychiatr Assoc J. 1994; 39: 49-54.

8. Garner DM, Olmstead MP, Polivy J. Development and validation of a multidimensional eating disorder inventory for anorexia nervosa and bulimia. Int J Eat Dis. 1983; 2: 1534. 
9. Drew AA, Paulosky CA. Psychological assessment of eating disorders and related features. In: Thompson JK. Handbook of Eating Disorders and Obesity, eds, Hoboken, NJ: Wiley \& Sons; 2003: 112-128.

10. Van Strien T, Schippers GM, Cox WM. On the relationship between emotional and external eating behaviour. Addict Behav. 1995; 20: 585-594.

11. Smith MC, Thelen MH. Development and validation of a test for Bulimia. J Consult Clin Psychol.1984; 52: 863-872.

12. Fairburn CG, Cooper Z. The Eating Disorder Examination (12th ed.). In: Fairburn CG, Wilson GT, eds, Binge eating:Nature, assessment and treatment. New York, NY: Guilford Press; 1993: 317-360

13. Wilson GT, Vitousek KM. Self-monitoring in the assessment of eating disorders. Psychol Assess. 1999; 11: 480-489.

14. Williamson DA. Assessment of eating disorders: Obesity, anorexia, and bulimia nervosa. Elmford, NY: Pergamon Press.

15. Pinto AM, Guarda AS, Heinberg LJ, DiClemente CC. Development of the Eating Disorder Recovery Self-Efficacy Questionnaire. Int J Eat Dis. 2006; 39: 376-384.

16. Scoffier S, Paquet Y, Corrion K, Arripe-Longueville F, (d'). French development and validation of the self-regulatory eating attitude in sports scale (SREASS). Scan J Med Sc Sp. 2009; 20: 696-705.

17. Thompson FE, Subar AF. Dietary assessment methodology. In: Coulston AM, Rock CL, Monsen ER, eds. Nutrition in the prevention and treatment of disease. San Diego, CA: Academic Press, 2001. p. 3-30.

18. Geier AB, Rozin P. Univariate and default standard unit biases in estimation of body weight and caloric content. J Exp Psychol: Appl. 2009; 15: 153-62. 
19. Krishna A. Interaction of senses. The effect of vision versus touch on the elongation bias. J Consum Res. 2006; 32: 557-566.

20. Chandon P, Wansink B. Is obesity caused by calorie underestimation? A psychophysical model of fast-food meal size estimation. J Mark Res. 2007; 44: 84-99.

21. Geier AB, Rozin P, Doros G. Unit bias: A new heuristic that helps explain the effect of portion size on food intake. Psychol Sc. 2006; 17: 521-525.

22. Black AE, Coward WA, Cole TJ, Prentice AM. Human energy expenditure in affluent societies: an analysis of 575 doubly-labelled water measurements. Am J Clin Nut. 1996; 50: $92-303$.

23. Ainsworth BE, Haskell WL, Herrmann SD, Meckes N, Bassett Jr DR, Tudor-Locke C, Greer JL, Vezina J, Whitt- Glover MC, Leon AS. 2011 Compendium of Physical Activities: a second update of codes and MET values. Med Sc Sp Exerc, 2011; 43:15751581.

24. Proudon H. Diondine. Available on: http://www.diondine.com/ . 2002.

25. Livingstone, M. B. E., \& Black, A. E. (2003). Markers of the validity of reported energy intake. The Journal of Nutrition, 133, 895S-920S.

26. Blundell JE. What foods do people habitually eat? A dilemma for nutrition, an enigma for psychology. Am J Clin Nut. 2000; 71: 3-5. 
Author Disclosure

\section{Role of Funding Sources}

5 French Ministry of Health and Sport, the Nation Institute of Sport and Physical Education and

6 the France Foundation. University of Nice Sophia-Antipolis, the French Ministry of Health

7 and Sport, the Nation Institute of Sport and Physical Education and the France Foundation

8 had no role in the study design, collection, analysis or interpretation of the data, writing the

9 manuscript, or the decision to submit the paper for publication.

\section{Contributors}

All authors designed the study and wrote the protocol, conducted literature searches and provided summaries of previous research studies, and conducted the statistical analysis. All authors contributed to and have approved the final manuscript.

\section{Conflict of Interest}

All other authors declare that they have no conflicts of interest.

\section{Acknowledgments}

The authors are grateful to the adults, adolescents and athletes for their participation and to the French Federation of Ice Skating for its support. They also sincerely thank Catherine Carmeni for help in the English translation. 4 
Appendix 1. The Virtual Self-Service Restaurant

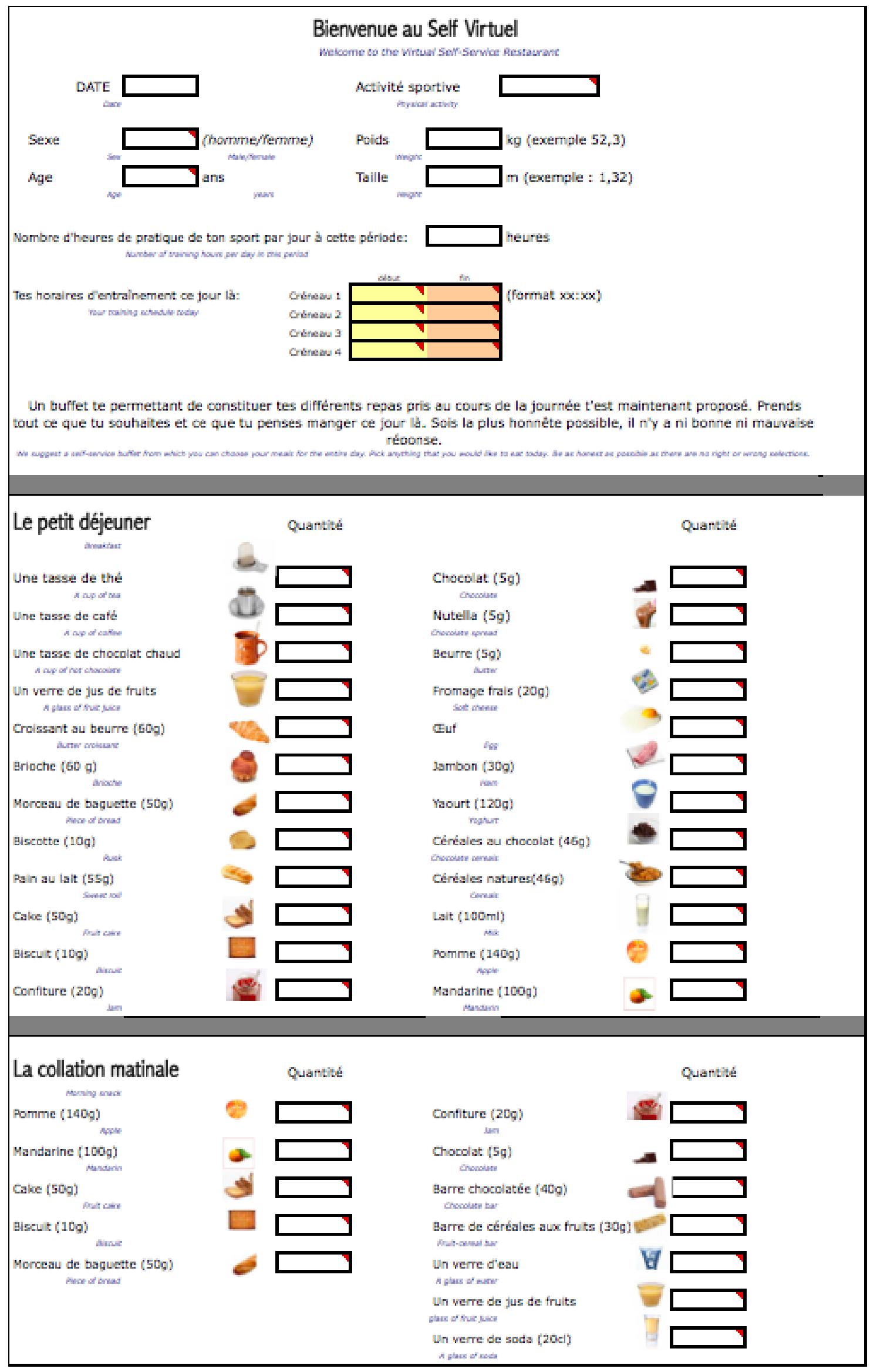




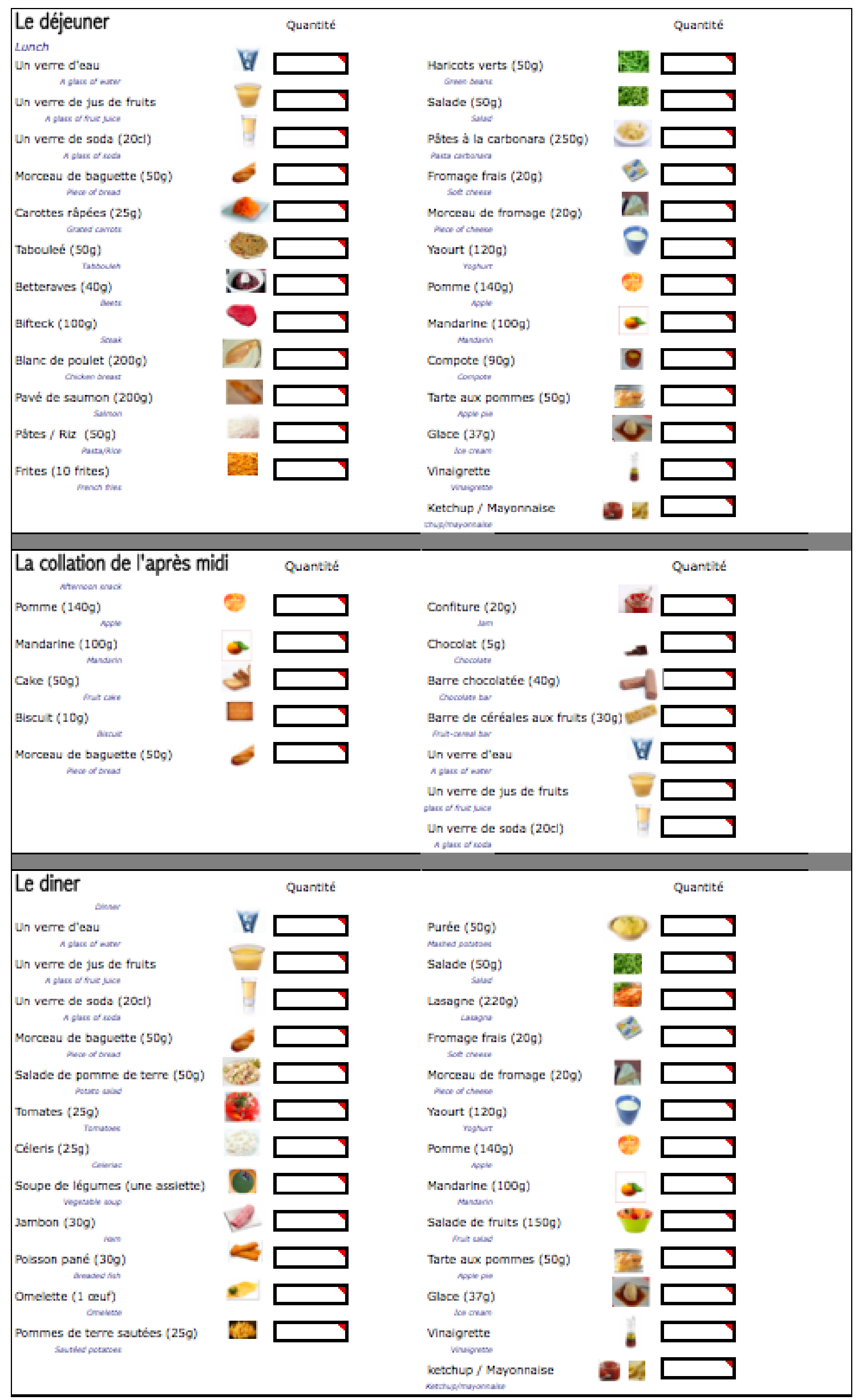




\section{Major concerns}

First, the aim of this study is to validate and develop a "new instrument to assess eating behaviours in athletes". Nevertheless, based on the introduction it is not possible to estimate what this "new" instrument really adds to the literature on this topic. Indeed, the introduction mainly focuses on eating disorders and self-report instruments on disturbed eating attitudes and/or self-regulation, whereas the main objective of this study is to examine food intake (see line 10 to 18, page 5). Several instruments that examine food intake or food frequency are available in the literature. Therefore, it is suggests that the authors (a) provide more information on current instrument on food intake or food frequency, (b) suggests pros and cons of these instruments for athletes at risk for eating disorders, and (c) more clearly explain what this instrument would add to knowledge on this topic.

$\rightarrow$ We acknowledge that our introduction did not include a review of the instruments used to assess food intake or food frequency. As suggested, we (a) now provide more information about these instruments, (b) underline their pros and cons for athletes at risk, and (c) justify more clearly the interest of our instrument for use by athletes to assess both their food intake and their energetic expenditure. See page 5 lines 3-10.

Second, the authors stated (lines 14 to 19, page 5) that "the development and validation of a specific tool, such as a virtual interface allowing subjects to project their eating habits, seemed necessary to better assess, explain and prevent eating disorders, especially among athletes". They should deeply explain why it is necessary and important.

$\rightarrow$ We have rewritten the sentence completed it. See page 5 lines 19-24.

Third, in the introduction the authors stated this instrument is devoted to athletes at-risk for eating disorders, but in the sample of this study no information are available on this phenomenon. We thus don't know whether the food intake patterns may be similar or not between athletes at-risk and non-at-risk, and if this instrument way helps to discriminate at-risk and non at-risk athletes. The same comments could be addressed to the athletes and non-athletes samples.

$\rightarrow$ We have rewritten the sentences dealing with this point in the abstract and the introduction in order to be clearer. The VSSR provides indirect information about the athlete's self-regulation of eating behaviors. Although it can be assumed that food intake patterns will differ between at-risk and not-at-risk athletes, in some specific cases (e.g., provoked vomiting), the food intake patterns might be similar. Therefore, it must be acknowledged that this instrument cannot fully discriminate atrisk and not-at-risk athletes. These limitations are now noted in the introduction and discussion sections of the paper. Thank you. See page 2 lines 5-7, page 1 lines 4-6, and page 3 lines 13-15.

Fourth, the results from this research should be rather viewed as preliminary and this should be clearly mentioned in the conclusion and in the title of the article. 
These results need to be replicated among a larger sample of participants that may also comprise athletes at-risk and non- at-risk for eating disorders. Additionally, the authors should explain how they could verify that this self-report instrument is significantly related to current or objective measure of food intake.

$\rightarrow$ As recommended, we have added the word "preliminary" to the title and have underlined the fact that the results should be viewed as preliminary in the conclusion. We have also added the suggested perspectives in the discussion of the manuscript, line 16 page 11.

\section{Minor concerns}

- In the abstract it is recommended to add a results' subsection.

- We have added this subsection in the English and the French abstracts.

- Page 3, line 7-9, "Eating disorders have become very common among those who participate in certain sports". Please provide more information on which sports, and clarify what very common mean (i.e., prevalence?).

- We have specified in which sports eating disorders are prevalent; see lines 4-5 page 3.

- Page 3, line 9-12, "These sports often require frequent weight checks and complex training. In many of these sports, thin, smaller athletes are desired". It is recommended to more clearly explain why "thin and smaller athletes are desired".

- More information about the need to be "thin and small" in aesthetic sports has been provided (page 3 lines 6-8).

- Page 3, line 42-47. In this statement "Indeed, the literature in social psychology and sport psychology indicates that disordered eating attitudes are developed from a complex interaction of personal and contextual factors [3-4]" it is recommended to provide examples of personal and contextual factors.

- We have added two examples of contextual and personal factors of disordered eating attitudes (page 3 lines 22-24).

- Page 3, line 49-50, it is recommended to use "disturbed eating attitudes and behaviours" rather than "eating attitudes".

- "Eating attitudes" has been changed to "disturbed eating attitudes and behaviours."

- Page 5, lines 31-32. Please could you explain what the following statement mean: "measuring actual food intake across eating attitudes and behaviors".

$\circ$ We have rewritten this sentence for greater clarity.

- Page 6, line 29-39. Could you give more information on the references used to estimate energy expended for physical activity? How this information was estimate? Did the authors use the compendium of physical activities 
provided by Ainsworth and colleagues (2000) to estimate energy expenditure? This should be clearly addressed.

- We apologize for not mentioning the reference. We used the compendium of physical activities from Ainsworth and colleagues (2000) to estimate energy expenditure. Page 7 lines 5 -10.

- Page 7, lines 8-26. The authors should explain (a) in which domain the members of the committee were expert? (b) why and how the five questions were chosen, and (c) why a criteria of $>3$ was retain as a satisfactory index.

- The members of the expert committee were three researchers in the field of disturbed eating attitudes in sport. We carried out a brainstorming session and we came to an agreement on five questions to assess the clarity of the instrument. We did not fix a criterion of $>3$ as a satisfactory index. We assessed the clarity of the items with a Likert scale and observed that the results were 3 or 4 for each question. The average was 3.80, which is a satisfactory index for clarity (Vallerand, 1989).

0 These points have been clarified in the Ms (see page 7 line 19 to page 8 line 5).

- Page 12, line 5-19. The authors should clearly explain why? "(a) This interface should be useful for research and to follow cohorts for epidemiological investigations intended to identify some risk factors for eating disorders. (b) The Virtual Self-Service Restaurant can also be used in the prevention of disordered eating by helping individuals to become more aware of their energy needs and the energy intake they virtually plan on a typical day. (c) The Virtual Self-Service Restaurant immediately picks up an imbalance in these two values and can then be used to better regulate feeding behavior".

- We have provided more information for each of these three points. See pages 12 and 13 .

- Page 12, line 22-49. In this paragraph the authors should clearly explain how and why this instrument would really help athletes to regulate their eating behaviour and prevent them from disturbed eating attitudes.

- We have provided more information in this paragraph, and we have also stressed some limitations. See page 13 lines 8-16. 